denser arrangement of Dr. Fleming was replaced by a single condenser, the arrangement being similar to that shown in Fig. 3 .

During the time that constructional work was in progress at Glace Bay, I carried out some tests with Poldhu over considerable distances, and these tests were greatly facilitated by the interest taken in them by the Italian Government, which placed the cruiser Carlo Alberto at my disposal.

During these experiments the interesting fact was observed that, when using waves of more than I000 metres in length, intervening land or mountains do not bring about any considerable reduction in the distance over which it is possible to communicate. Thus messages and Press despatches were received from Poldhu at the positions marked on the map (Fig. 9), which map is a copy of the one accompanying the official report of the experiments (Revista Marittima, Rome, October, I902).

In December, 1902, messages were for the first time exchanged at night between the stations at Poldhu and Glace Bay, but it was found that communication was exceedingly difficult and untrustworthy from England to Canada, whilst it was good in the opposite direction. The reason for this is that the Glace Bay station was equipped with more powerful and more expensive machinery-a condition rendered possible by the subsidy granted by the Canadian Government; whilst as regards Poldhu, owing to

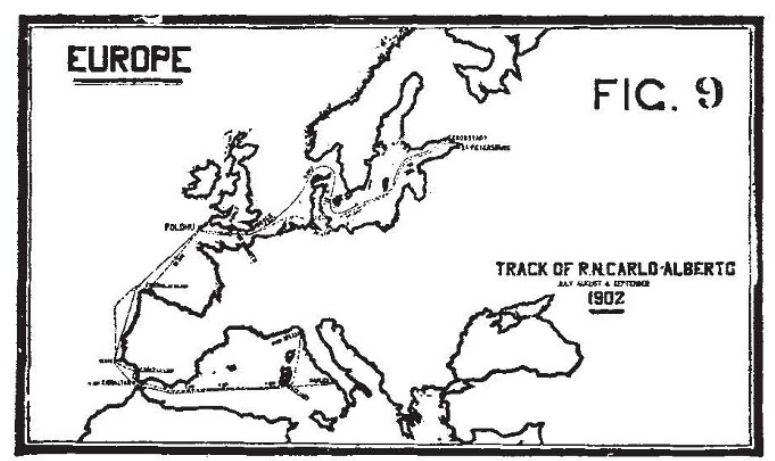

the uncertainty of what might or might not be the attitude of the British Government at that time towards the working of the station, my company was unwilling to expend large sums of money for the purpose of increasing its range of transmission.

As, however, messages could be sent then for the first time by wireless telegraphy from Canada to England, inaugural messages were dispatched to the Sovereigns of England and Italy, both of whom had previously given me much assistance and encouragement in my work, and who, by their gracious replies, attested their appreciation of the results which had been achieved. Other messages were also sent to England by the Government of Canada.

Further tests were shortly afterwards carried out with the long-distance station at Cape Cod, in the United States of America, and a message from President Roosevelt was transmitted from that station to $\mathrm{His}$ Majesty the $\mathrm{King}$ in London.

It is curious to note, in regard to the transmission of this message, that the energy employed at Cape Cod was barely io kilowatts, and it was not anticipated that this amount of energy would be sufficient to carry direct to Poldhu. The message was therefore transmitted from Cape Cod, instructions having been given to the operators at Glace Bay to be on the look-out, and to repeat wirelessly on to Poldhu any message received from Cape Cod, and my assistant, Mr. P. J. Woodward, at Poldhu, took in the message on one of my magnetic detectors. ${ }^{x}$ The electromagnetic waves conveying this message travelled, therefore, 3000 miles through space over the Atlantic, which distance included about 500 miles of land, following an arc of 45 degrees on a great circle.

(To be continued.)

1 Proc. Roy. Soc., Ixx., p. 34r, " Note on a Magnetic Detector of Electric Waves which can be employed as a Receiver for Space Telegraphy." NO. 2060 , VOL. 80$]$

\section{THE PHYSICS OF GOLF}

I $\mathrm{N}$ two articles recently published in the Times (March 16 and 23) Sir Ralph Payne-Gallwey has extended in an interesting way the earlier results in the physics of golf which the late Prof. Tait communicated to NATURE between the years 1887 and 1894 . In Sir Ralph's experiments the golf balls were projected mechanically by means of a catapult, the ball being either thrown from a cup at the end of the rotating arm or hit off as it hung at the end of a gossamer thread by a blow from the arm. In either case the initial conditions of projection must differ from those which exist in the ordinary mode of propulsion, and it would have been interesting to have had some comparisons. As Tait conclusively showed, the great factor in long driving was the underspin communicated to the ball by the impact of the club in a line below the centre of gravity. Hence the value of the roughened ball, causing not only a better grip between the ball and the club, but also making more efficient the effect of the resistance of the air in producing the uplifting force. Sir Ralph PayneGallwey shows experimentally that the ball must not be too much roughened, and that, indeed, a distinctly less roughening than is usual is sufficient to ensure the maximum carry. It is obvious that with a very rough surface the resistance of the air will rapidly cut down the rotation, and thereby diminish the transverse force which lifts the ball against gravity.

Sir Ralph does well in directing attention to the necessity of a truly centred ball. The golfer can readily test the ball in this respect by floating it in water (Tait used to use mercury) and noting whether or not it comes quickly to the same position. If it comes quickly always to the same position it is badly centred, and must be rejected. As all bowlers know, the lack of truc centring will give a bias which cannot but produce inaccurate putting. In the flight through the air the bad effects due to the centre of gravity being non-coincident with the centre of figure will probably come into evidence because of the shifting of the axis of rotation. Such a badly centred ball, when projected from the tee, will in general be sent off rotating about an axis which, though initially horizontal, is not a principal axis of inertia. Of necessity precessional motion will result, and the axis of spin will move away from its horizontal position. The phenomena which lead to the evils of slicing and pulling will at once declare themselves. Moreover, if the precessional motion be rapid enough, it is conceivable that the ball might swerve in one direction during one part of its course, but in the other direction during another part of the same trajectory. A sinuous flight is. inderd, occasionally observed, but is generally attributed to the direct action of the wind. Sir Ralph Payne-Gallwey does direct himself touch upon the ultimate dynamics of the problem, but confines himself entirely to the direct teaching of experiment. His conclusions are of great practical value to all devotees of the game, and it would be well if the manufacturers of golf-balls would test every ball they put on the market by the simple methods described by him.

\section{UNIVERSITY AND EDUCATIONAL INTELLIGENCE}

THE Bristol Town Council has decided to contribute in the proportion of one penny in the pound on the rate, or about 7oool. per annum, towards the support of the proposed university for Bristol and the West of England for which more than $200,000 l$. has been subscribed, mainly by members of the Wills family.

THE estimate of the amount required in the year ending March 3I, 1910, for grants in aid of the expenses of certain universities and colleges in Great Britain is $217,400 l$. The following are the sub-heads under which this vote will be accounted for by the Treasury. Grants in aid, universities and colleges:-(A) University of London, Soool.; (B) Victoria University of Manchester, zoool.; (C) University of Birmingham, 200ol.; (D) University of Wales, 4000l.; (E) University of Liverpool, zoool.: (F) Leeds University, 200ol.; (G) Sheffield Uni- 
versity, 2000l.; (H) Scottish universities, 42,00ol.; (I) colleges, Great Britain, roo,oool.; (J) university colleges, Wales, r2,0ool.; (K) Welsh university and colleges, additional grant, ${ }_{15}, 000 l$; increase, ${ }_{15}, 000 l$. University College of North Wales (building fund), decrease, 20,000l. Provision is made as follows in other estimates for expenditure in connection with the University of London :-buildings, external maintenance and repairs, $3358 l$. ; rates, $4500 l$. ; non-effective, $1317 l$. ; total, 9175l.

ThE Times announces that " the German Aërial Navy League is organising a school for aëronauts which, it is said, will be opened at Friedrichshafen on October 1 of this year. The object of the school is to provide the necessary scientific and practical training for the crews of military and other airships. Only those who have been through an 'intermediate' school and, in addition, have worked for a year in engineering shops, will be admitted as pupils. The course will extend over three years, of which the first will be devoted to theoretical instruction, the second to work in a construction yard, and the third to ascents in airships and flying machines." This announcement will be read with the more interest as a somewhat similar project forms a part of the programme of the recently formed Aërial League of Great Britain, the inaugural meeting of which at the Mansion House was so highly successful. It is much to be hoped that the promoters of the English scheme will succeed in maintaining the same high standard of admission, and the same length of training, that are contemplated in the above notice. It would be highly undesirable that an institution founded for the training of aëronauts should have to waste its resources by providing classes in elementary calculus and mechanics such as can be found at any technical college.

THE National Union of Teachers held its annual conference of delegates at Morecambe from April 1o to I5 $_{5}$ and the meeting was thoroughly successful and the discussions full of interest, notwithstanding the rather unusual circumstance that there was no new Education Bill to be considered. The president, Mr. C. W. Hole, delivered the inaugural address, in the course of which he stated that the elementary schools have made great progress during recent years. The ancient system of payment by results has passed away, leaving all concerned happier and better for its disappearance; the liberty and confidence reposed in the teachers have resulted in the children being, not only rationally instructed, but also more properly educated. It remains for the Government to provide financial assistance in order that the size of the classes may be reduced and the staff rendered efficient in number and quality. In this connection Mr. Hole warmly approved Mr. Runciman's recent staffing circular. Resolutions were carried unanimously (I) in favour of larger grants from the National Exchequer; (2) regretting attempts made by certain local authorities to repudiate settled contracts of teachers in their service. At the sectional meetings papers were read by Mr. C. H. Wyatt and Mr. Ernest Gray on the supply and training of teachers, by Mr. A. R. Pickles on leaving examinations and scholarship competitions, and by $\mathrm{Mr}$. Charles Bird on the teaching of handwork. $\mathrm{Mr}$. Pickles quoted with approval the report of the British Science Guild on the relations of primary and secondary education, particularly the recommendation that the reports of teachers should supersede largely the present system of estimating ability by examinations.

THE Colonial Conference in 1907 pronounced in favour of reciprocity between the Governments and examining bodies throughout the Empire. The council of the Surveyors' Institution has taken an important step forward by submitting a memorandum to the Colonial Secretary, which Lord Crewe has approved and dispatched to the officers administering the Governments of Canada, Newfoundland, Australia, New South Wales, Victoria, Queensland, South Australia, Western Australia, Tasmania, New Zealand, Cape of Good Hope, Natal, Transvaal, and Orange River Colony. The memorandum states that under existing conditions a surveyor has to pass examinations and comply with requirements, varying in different parts of the Empire, before he is allowed to practise. It is

$$
\text { NO. 2060, VOL. 80] }
$$

hoped, as a result of the present movement, to arrive at a uniform standard of qualification. A surveyor would then, having taken his diploma in England or one of the colonies, be eligible to practise in any part of the Empire, subject to an examination in the local land laws and conditions. In the event of an Imperial conference of surveyors being held, it will take place at the Surveyors' Institution, and the chief points, so far as they have been formulated, for discussion would probably be the desirability of establishing reciprocity throughout the Empire :(a) that a candidate must have matriculated at some recognised university, or passed an equivalent examination; (b) that an examination in the theory of land surveying be then taken, the standard of this examination to be as high as that now in force in South Africa; $(c)$ that the candidate be then required to pass an examination in practical surveying, and that he be ineligible to sit for this final examination until he has had at least two years' experience with a practising surveyor.

\section{SOCIETIES AND ACADEMIES. LONDON.}

Royal Society, December ro, 1908 - "The Specific Heat of Air and Carbon Dioxide at Atmospheric Pressure, by the Continuous Electrical Method, at $20^{\circ} \mathrm{C}$. and at $100^{\circ} \mathrm{C}$." By W. F. G. Swann. Communicated by Prof. H. L. Callendar, F.R.S.

The continuous electrical method possesses two main advantages over the method of mixtures; it enables the specific heats to be measured over small ranges of temperature, and further, the elimination of the heat loss does not depend upon the results of a set of experiments in which the conditions are different to those which hold in the main experiments. The mean of a large number of measurements of the specific heats, agreeing to about I part in 1000, gave the following results :- -

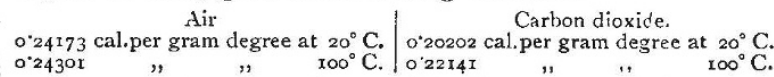

An accurate comparison with the values deduced on theoretical considerations from Joly's measurements at constant volume can be made in the case of air, and the agreement is shown to be nearer than to I part in 1000 . The comparison can only be made in a rough manner for carbon dioxide, and the agreement is to I per cent.

The results obtained are about 2 per cent. higher than those obtained by former investigators. The experiments of Regnault are discussed as a typical example, and it is pointed out that an uncertainty amounting to 5 per cent. (tending to make the results too low) probably exists in those experiments, owing to the fact that the heat loss was determined by a set of observations in which the conditions were different to those which held in the main experiments.

March 25.- Sir Archibald Geikie, K.C.B., president, in the chair.--Liberation of helium from radio-active minerals by grinding: J. A. Gray. (I) Helium is liberated from thorianite, and a liberation of 28 per cent. has been cffected; (2) the smaller the mineral is ground the more helium is liberated; (3) this liberation has a temporary limit when the mineral is reduced to a size of about $3 \mu$; (4) it is impossible to say how the remaining $7^{2}$ per cent. of helium is contained in the mineral, and to how much finer than $I \mu$ the mineral would have to be reduced to liberate the helium.-The expulsion of radio-active matter in the radium transformations: Sidney Russ and $W$. Makower. When the radium emanation is transformed into radium $\mathrm{A}$, the process is accompanied by the emission of $\alpha$ particles with a velocity of $\mathrm{I} .70 \times 10^{9}$ centimetres per second. The portion of the atom from which the $\alpha$ particle has been emitted, which constitutes the radium $A$, must therefore recoil in a direction opposite to that in which the $\alpha$ particle is projected. If we further consider that the mass of the a particle is $4(\mathrm{H}=\mathrm{I})$, and that of the active deposit of the order 100, it follows that at the moment of its formation this product must be travelling with a velocity of the order $10^{7}$ centimetres per second. In ordinary circumstances, when the emanation is mixed with air at atmospheric pressure, the radium it particle 